\title{
Optimization of Biohydrogen Production with Biomechatronics
}

\author{
Shao-Yi Hsia ${ }^{1}$ and Yu-Tuan Chou $^{2}$ \\ ${ }^{1}$ Department of Mechanical and Automation Engineering, Kao Yuan University, Kaohsiung 821, Taiwan \\ ${ }^{2}$ Department of Applied Geoinformatics, Chia Nan University of Pharmacy \& Science, Tainan 717, Taiwan \\ Correspondence should be addressed to Shao-Yi Hsia; syhsia@cc.kyu.edu.tw
}

Received 10 February 2014; Accepted 19 February 2014; Published 26 March 2014

Academic Editor: Teen-Hang Meen

Copyright ( $(2014$ S.-Y. Hsia and Y.-T. Chou. This is an open access article distributed under the Creative Commons Attribution License, which permits unrestricted use, distribution, and reproduction in any medium, provided the original work is properly cited.

\begin{abstract}
Massive utilization of petroleum and natural gas caused fossil fuel shortages. Consequently, a large amount of carbon dioxide and other pollutants are produced and induced environmental impact. Hydrogen is considered a clean and alternative energy source. It contains relatively high amount of energy compared with other fuels and by-product is water. In this study, the combination of ultrasonic mechanical and biological effects is utilized to increase biohydrogen production from dark fermentation bacteria. The hydrogen production is affected by many process conditions. For obtaining the optimal result, experimental design is planned using the Taguchi Method. Four controlling factors, the ultrasonic frequency, energy, exposure time, and starch concentration, are considered to calculate the highest hydrogen production by the Taguchi Method. Under the best operating conditions, the biohydrogen production efficiency of dark fermentation increases by $19.11 \%$. Results have shown that the combination of ultrasound and biological reactors for dark fermentation hydrogen production outperforms the traditional biohydrogen production method. The ultrasonic mechanical effects in this research always own different significances on biohydrogen production.
\end{abstract}

\section{Introduction}

Because hydrogen is clean and sustainable and has high thermal energy, research on hydrogen energy has recently been emphasized in academia and industry. Traditional hydrogen production methods include the thermochemical and electrochemical methods, which are highly energy intensive, resulting in expensive and polluting production. However, the biological method applies anaerobic microorganism (primarily clostridium bacteria) to wastewater treatment, simultaneously converting the organic matter in wastewater into usable hydrogen. This method not only solves the problem of environmental pollution but also develops clean hydrogen energy and is an economic and competitive method of hydrogen production.

Reviewing the previous development of destructive ultrasound biological effects, Coakley et al. [1] discovered the cavitation of Amoebae under the ultrasonic effects with the frequency $1 \mathrm{MHz}$ and the intensity $515 \mathrm{~W} / \mathrm{cm}^{2}$ in 1971 , when the number of cells obviously decreased after the irradiation. Coakley and Dunn [2], in the same year, discovered the irrelative relationship between the extraction of DNA with the irradiation of frequency $1 \mathrm{MHz}$ and intensity $200-$ $288 \mathrm{~W} / \mathrm{cm}^{2}$ and transient cavitation, but the molecular weight of DNA reduced with the increasing transient cavitation when the energy exceeded $500 \mathrm{~W} / \mathrm{cm}^{2}$. Coakley et al. [3] studied the ultrasonic cavitation effects on the inactivation of enzymes in 1973 and found out the less influence of cavitation effects on catalase under the continuous irradiation of $20 \mathrm{kHz}$ ultrasound but the inactivation of alcohol dehydrogenase and lysozyme with increasing exponential rate. Ahmed and Russell [4] explored the death of microorganisms with ultrasound and hydrogen peroxide in 1975. Dooley et al. [5] irradiated mice's thymocytes suspension with continuous and pulsed ultrasound under the frequencies of $0.5 \mathrm{MHz}$ and $1 \mathrm{MHz}$ in 1983 and argued that the ultrasound transducer used in medicine did not reveal absolute correlations with the damage of suspension cells. Van [6] discussed the flow of cysts and oocytes of protozoa by irradiating with ultraviolet and ultrasound in 2002. Broda [7] reduced the bacillaceae attached in the test tubes or on the resin by increasing the temperature and adding high-acid disinfectants as well as 
increasing the temperature and adding ultrasound irradiation to study and observe the survival rate of the bacteria in 2007.

Regarding biohydrogen production, Lin [8] performed hydrogen production on wastewater sludge and developed an immobilized cell system for programming sludge in hydrogen production and immobilizing cells with different materials and hydrogen production, thus identifying the optimal method for producing repeated batches of immobilized cell hydrogen. Chen [9] cultivated anaerobes using carbohydrate and waste-water sludge via CSTR (the reaction volume 4l) to generate hydrogen. Wang [10] combined mixed bacteria with starch and starch hydrolysis as the carbon source to design a dark fermentation hydrogen production system and found starch hydrolysis to have a higher hydrogen production rate than starch. Hydrolyzing starch thus was the key to biohydrogen production cost in developing hydrolyzing amylase. Modigell et al. [11] designed a high-efficiency and low-energy consumption biohydrogen production method with membrane contact and nonporous polymer membranes that not only could effectively absorb the byproduct, carbon dioxide, but also could prevent high pressure and high fodder in the polluted natural liquid under aseptic conditions during hydrogen production and enable harmful materials, like monoethanolamine (ethanolamine), being the carrier liquid to pass the test of different membranes and be optimized and commercially applied. Antonopoulou et al. [12] developed sweet sorghum with glucose as the material under distinct hydraulic retention time in which both glucose-fermentation hydrogen production and fermented waste liquid were utilized to generate methane. The experiment proved that the highest hydrogen production rate $\left(2550 \mathrm{mLH}_{2} / \mathrm{d}\right)$ appeared at the retention time of $6 \mathrm{hrs}$, while the highest amount $\left(10.4 \mathrm{LH}_{2} / \mathrm{kg}\right)$ appeared at the glucose retention time of $12 \mathrm{hrs}$. To optimize methane generation, about $291 \mathrm{CH}_{4} / \mathrm{kg}$ glucose was required during fermentation. The research outcomes also demonstrated that using glucose for hydrogen production could efficiently generate methane. In this case, using gas to replace fossil fuels became an ideal method. Kotay and Das [13] also mentioned the important contribution of biohydrogen production to renewable energy in the future, which was particularly suitable for smaller scale and scattered systems. Additionally, the combination of agricultural and industrial activities and waste treatment facilities for biohydrogen production was essential in maintaining global electricity supply, and it was considered a substitute for fossil fuels and a fuel with multiple applications. Manish and Banerjee [14] considered hydrogen a reliable energy since various methods could be established to promote the development of renewable energy. For instance, light and dark fermentation, or a combination of the two, could provide a feasible method of biohydrogen production and confirm various related techniques and design parameters. The results of using such biological methods for hydrogen production and sugar cane juice for nutrient showed that byproducts increased with biohydrogen production efficiency. In terms of the biological experiment designed using the Taguchi Method, Su [15] planned ultrasonic mechanical effect exposure and light source adjustment to hatch fairy shrimps

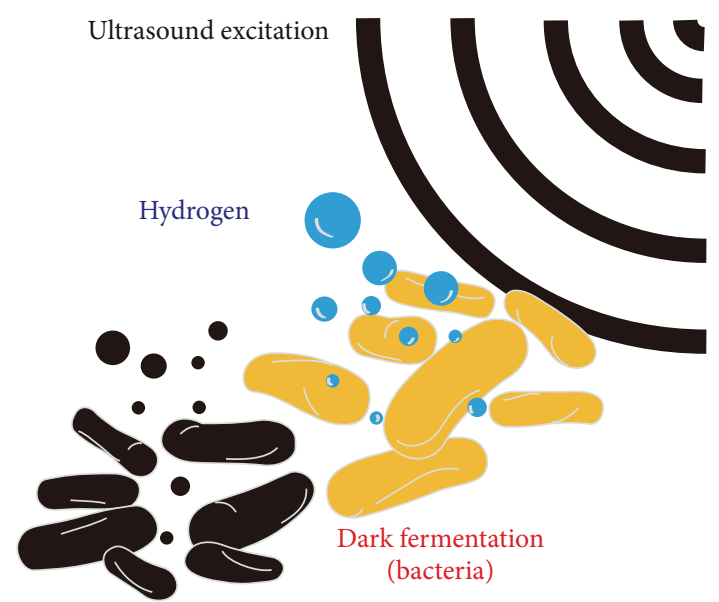

FIGURE 1: Sketch map of biohydrogen production with biomechatronics.

and optimize the parameters. The outcomes identify optical wavelength as the main influence on hatchability.

Research on the effects of ultrasound exposing bacillaceae has not been discussed. This study thus attempted to develop a suitable medium composition and perform dark fermentation hydrogen production with biological reactors and ultrasonic mechanical effect shown on Figure 1, where the Taguchi Method was combined to discuss the optimal hydrogen production conditions in the process, and aimed to further understand the effects of ultrasound on microorganisms.

\section{Basic Theory}

In response to depleting fossil fuel energy and to meet pollution reduction targets, it is necessary to develop new energy technologies that match modern demand. Among all emerging energy sources, hydrogen appears to have the fewest side effects and pose the least environmental harm. Looking at traditional thermochemical methods and electrochemical methods reveals that hydrogen production exhibits strengths and weaknesses in stability, security, and production; however, biohydrogen production represents a natural and potential hydrogen production method. Generally, anaerobe (primarily bacillaceae-clostridium) can transform organic matter into usable hydrogen during wastewater treatment via the biological method and also contributes to reducing pollution. Biological dark fermentation hydrogen production thus is considered a favorable choice as anaerobes can decompose organic compounds to generate hydrogen without a light source and are easily incorporated into waste-water treatment so that a practical form of renewable energy can be developed while processing environmental pollution. When the Taguchi Method is applied to optimize hydrogen production it becomes an economical hydrogen production method. Focused on ultrasound, biological effect, and the Taguchi Method, this chapter further discusses the correlations in this study. Figure 2 plotted the flowchart of the biohydrogen production experiment. 


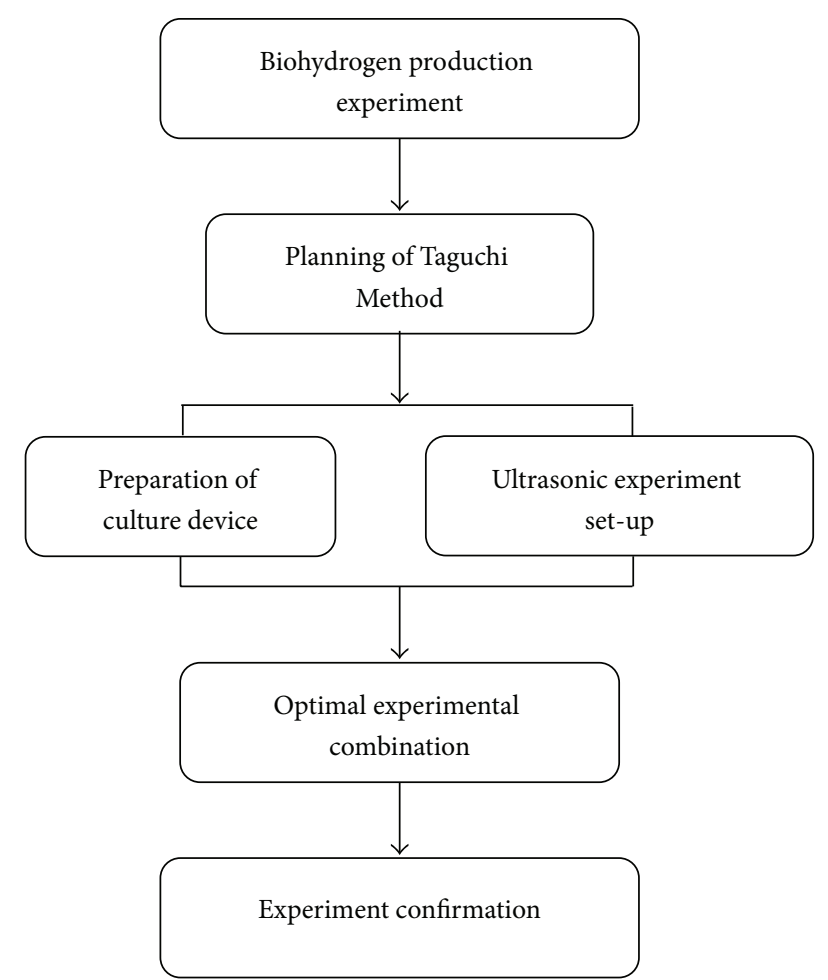

FIGURE 2: Flowchart of the biohydrogen production experiment.

2.1. Principles Underlying the Biological Application of Ultrasound. Ultrasound has been applied to real world applications in recent decades and has been utilized to improve human life. Compared with certain animals, such as bats and whales, people still learn from the biosphere to improve production and life quality. Research on animal behavior models could provide improvements in mechanical design and logistic processing models. Consequently, it becomes necessary to understand the effects of ultrasound on organisms. Ultrasound communicates in transmission media and can generate a series of effects and influences, including organism-related thermal and nonthermal effects. The latter are further divided into mechanical effects and empty-hole effects.

2.1.1. Thermal Effect. When transmitting through viscous substances, ultrasonic energy is partially absorbed by friction and relaxation among molecules or lattices. The energy thus absorbed is transformed into heat and increases the temperature of the substance involved. As seen for physiological tissues, heat effects can boost metabolism but harm physiological tissues with these different effects depending on ultrasonic intensity and exposure time on physiological tissues. Thermal effect refers to micromassage causing tissues to generate ultrasonic efficacy and thus produce different heat energy and also refers to the increased heat production by the body after eating owing to the metabolic energy cost of digestion. It is considered diet-induced thermogenesis.

2.1.2. Nonthermal Effect. The nonthermal effects of ultrasound include radiation pressure, radiation force, acoustic torque, acoustic streaming effect, and cavitation. The basic source of these effects is the peripheral pressure change caused by ultrasound. The cavitation produces the largest effect and thus can break the cell structure, collapse aerosol cells, or tear solid physiological tissues. Rayleigh-Plesset announced the mathematical movement model for the inner cavitation vibration of incompressible liquid in 1949 [16]. Applying such a theory to calculate the appearance of dark fermentation rod hydrogen producing bacteria and the internal tissue could result in the natural frequency in the physical activation so as to observe the activation effects by setting different pulse intensity for the vibration. The radius $R_{0}$, surface tension $\sigma$, heat capacity ratio $\gamma$, density $\rho$, viscosity coefficient $\eta$, and pressure $P_{0}$ of the bacteria are substituted for the following equation to calculate the natural frequency:

$$
\left(\omega_{r}^{\prime}\right)^{2}=\frac{1}{\rho R_{0}^{2}}\left[3 \gamma\left(P_{0}+\frac{2 \sigma}{R_{0}}\right)-\frac{2 \sigma}{R_{0}}\right]-\left(\frac{2 \eta}{\rho R_{0}^{2}}\right)^{2} .
$$

Collapse of cavity cells can cause high pressure and temperature change and hence biochemical reactions. Generally, the nonthermal effect can be separated into the mechanical effect and empty-hole effect.

(a) Mechanical Effect. The mechanical oscillation effect describes ultrasound generating extendable change in tissues via a process similar to massage and is also called micromassage. During transmission in media, oscillation of spatial particles in the ultrasonic path is induced so that particles present faster movement, displacement of acoustic pressure, tensile stress, compressive stress, and expansion or contraction.

(b) Empty-Hole Effect. When applying strong ultrasound in liquid, excessive pressure and negative pressure occur because ultrasound is a compressional wave. Negative pressure breaks the liquid, causing empty holes and cavitation. Such bubbles comprise liquid steam or gas in the liquid. Bubbles are unlikely to break when the radius reaches a certain size. Some bubbles might break during oscillation, resulting in shock waves and high temperature through which cavitation causes various physical or chemical actions in the liquid.

2.1.3. Effects of Ultrasound on Cells. Ultrasound can increase cell membrane permeability (permeability is the ability of water to pass through a material; water passes more easily through materials with good permeability and cannot pass easily through those with poor permeability). The experimental findings showed that constant and pulse ultrasound change tissue internal and external osmotic pressure (osmosis refers to the ability of a matter to pass through the membrane or not) and that cell stimulation needs to be changed to enhance the metabolism and reaction process and change the $\mathrm{pH}$ of the human body.

Ultrasound enhances tissue regeneration and the effects of peripheral nerves and significantly influences the conduction velocity of peripheral nerves. The major factor is the diathermanous effect of ultrasound. Higher intensity 
ultrasound generates a transmission area that proves the sensibility of nervous tissues toward ultrasound.

2.2. Biohydrogen Production Method and Classification. Generally, based on nutrient category and the distinct formula, hydrogen production methods can be classified as thermochemical, electrochemical, and biological. The thermochemical and electrochemical methods have some weaknesses, such as large energy consumption and instability. Biohydrogen production can transform organic waste into energy via biodegradation and biotransformation. This method not only can solve environmental pollution and generate hydrogen energy but is also considered the best method of energy production for achieving sustainable environmental protection and commercial value. Biohydrogen production can use numerous microorganisms, for example, green algae, cyanobacteria, photosynthetic bacteria, and fermentation bacteria. The biological method includes photosynthesis, light fermentation, and dark fermentation. The dark fermentation applied in this study utilizes anaerobic bacteria to decompose organic matters, which is considered the traditional anaerobic fermentation method.

Regarding the organic matter in wastewater, the anaerobic bacteria contain hydrolytic bacteria, hydrogen production acetic acid bacteria, acetic acid synthetic hydrogen production bacteria, and methane bacteria. In the traditional anaerobic digestion process, the organic matter converts into methane and carbon dioxide, and hydrogen is generated using acid production metabolism, but acetic acid bacteria and methane bacteria consume hydrogen so that hydrogen becomes the intermediary in the metabolic pathway. In this case, the concentration of hydrogen accumulated was lower than in the traditional anaerobic digestion process. In terms of anaerobic hydrogen production bacteria, clostridium bacteria is common and merely needs preprocessing sludge to inhibit or destroy methane bacteria activity, which can be achieved through heat or acid-alkali treatment. Having glucose as the substrate, the equation for hydrogen production of anaerobic bacteria is as follows:

$$
\begin{gathered}
\mathrm{C}_{6} \mathrm{H}_{12} \mathrm{O}_{6}+2 \mathrm{H}_{2} \mathrm{O} \longrightarrow 2 \mathrm{CH}_{3} \mathrm{COOH}+2 \mathrm{CO}_{2}+4 \mathrm{H}_{2} \\
\mathrm{C}_{6} \mathrm{H}_{12} \mathrm{O}_{6} \longrightarrow \mathrm{C}_{3} \mathrm{H}_{7} \mathrm{COOH}+2 \mathrm{CO}_{2}+2 \mathrm{H}_{2}
\end{gathered}
$$

where $\mathrm{C}_{6} \mathrm{H}_{12} \mathrm{O}_{6}$ is glucose, $\mathrm{CH}_{3} \mathrm{COOH}$ is acetic acid, and $\mathrm{C}_{3} \mathrm{H}_{7} \mathrm{COOH}$ is butyrate.

The traditional anaerobic digestion process hydrolyzed complex organisms (cellulose polysaccharide or protein) into small molecules (carbohydrate amino acid) which were converted into hydrogen, carbon dioxide, acetate, propionate, butyrate, and alcohols through fermentation. The propionate, butyrate, and alcohols were converted into hydrogen, carbon dioxide, and acetate through fermentation, while the hydrogen and carbon dioxide were converted into acetate by acetic bacteria and the acetate was further converted into gas by methane bacteria. The process using anaerobic bacteria yields a better hydrogen rate if the main metabolite is organic acid than if it is alcohols or ketones. Electrons are transferred to higher reduced form outcomes such as alcohols or ketones, thus resulting in a low hydrogen rate.

\subsection{Hydrogen Production Strains and Metabolism Path}

2.3.1. Introduction to Bacillaceae. Short stemmed bacillaceae is one of the bacteria that are best able to produce hydrogen. Under anaerobe, the best production occurs at $25 \sim 60^{\circ} \mathrm{C}$ and neutral $\mathrm{pH}$, and it forms endospore and becomes dormant in an unsuitable environment. Bacillaceae is spore-producing with a particular structure and grows in thalli. Each thallium can grow a spore at its end that is wider at the end and also differs from other thalli.

Spore formation is a severe physiological and biochemical change for thalli. Both thalli and spores exhibit two nuclei and form two cell membranes, as the precursor spores. When the cells take the first step, they merely form endospores only when the thick wall of precursor forms is complete. The entire process lasts about $8 \sim 10$ hours.

2.3.2. Anaerobic Fermentation Metabolic Pathway. According to Wang [10], increasing the contents of formate, pyruvate, and nicotinamide adenine dinucleotide reduced form (NADH) enhances hydrogen production. Tanisho and Das reported increased NADH and hydrogen. Consider

$$
\begin{gathered}
\mathrm{CH}_{3} \mathrm{COCOOH}+\mathrm{HCoA} \longrightarrow \mathrm{CH}_{3} \mathrm{COCoA}+\mathrm{HCOOH} \\
\mathrm{HCOOH} \longrightarrow \mathrm{H}_{2}+\mathrm{CO}_{2} \\
\mathrm{NADH}+\mathrm{H}^{+} \longrightarrow \mathrm{H}_{2}+\mathrm{NAD}^{+}
\end{gathered}
$$

\subsection{Taguchis Optimization Experiment}

2.4.1. Taguchi's Orthogonal Array. Taguchi's Orthogonal Array describes the creation of a pair of parameters from all levels at two column intervals in the experimental table, where each composition exhibits the same frequency. The Classical Orthogonal Array is named after $L_{a}\left(b^{c}\right)$ and presents that the experiment contains $c$ factors, each of which has $b$ levels for an experiment. Orthogonal Array compromises on experimental cost and precision, and fewer experiments are needed to achieve useable statistical information. Nevertheless, Orthogonal Array experiments are not Full Factorial experiments. The "bias" cannot be fully eliminated but is acceptable since not all levels of compositions appear on the Orthogonal Array. The optimal composition therefore might not occur in the experimental group.

2.4.2. Signal-to-Noise Ratio ( $S / N$ Ratio). $S / N$ ratio is frequently used as the quality index in the Taguchi Method, demonstrating the effects of errors at the process or product level. According to different quality characteristics, various $S / N$ ratio formulas are formed, including Nominal-the-best, Smaller-the-better, and Larger-the-better. Both Smaller-thebetter and Larger-the-better were applied in this study, and the Smaller-the-better $S / N$ ratio is shown as follows:

$$
\frac{S}{N_{\mathrm{SB}}}=-10 \log \left[\frac{\sum_{i=1}^{n}\left(y_{i}\right)^{2}}{n}\right]=-10 \log \left(\bar{y}^{2}+S_{n}^{2}\right) .
$$


The larger-the-better $S / N$ ratio is shown as

$$
\frac{S}{N_{\mathrm{LB}}}=-10 \log \left[\frac{\sum_{i=1}^{n}\left(1 /\left(y_{i}\right)^{2}\right)}{n}\right],
$$

where $y_{i}$ shows the experimental values, $\bar{y}$ the mean experimental value, $S_{n}$ the standard deviation, and $n$ the number of experimental times.

This study combined the mechanical effect generated by ultrasound and biohydrogen production technology and applied the Taguchi Method to design the experiment and analyze the parameter relations to optimize the effect. In the process, dark fermentation was utilized for hydrogen production based on several advantages as follows.

(1) Fermented strains have rapid hydrogen metabolism.

(2) It could rapidly and continuously produce hydrogen from organic matter.

(3) It shows a favorable growth rate on general microbial systems.

For these reasons, dark fermentation hydrogen production appears to obtain better benefits in terms of microorganism quality and quantity than does photosynthesis bacteria hydrogen production. Regarding the mechanical effect of ultrasound on dark fermentation, frequency, energy, number of exposures, and duration are the changeable parameters. Additionally, $\mathrm{pH}$, temperature, nutrient content, starch, and stir speed can be adjusted to match specific organisms. The experiment designed three parameters for ultrasonic mechanical effect using the Taguchi Method, namely, frequency, intensity, and exposure time, to observe and analyze the effects on biohydrogen production.

\section{Experimental Method and Procedures}

3.1. Experimental Method. The ultrasonic system and biohydrogen production equipment utilized for this experiment are described as follows.

3.1.1. Ultrasonic System. The experimental structure in which ultrasound was used for hydrogen production is shown in Figure 3. In the research, the physical parameters of microorganisms covered surface tension $\sigma=72.75 \mathrm{dyn} / \mathrm{cm}$, heat capacity ratio $\gamma=1.4$, water density $\rho=1 \mathrm{~g} / \mathrm{cm}^{3}$, viscosity coefficient $\eta=9.197 \times 10^{-3} \mathrm{~g} / \mathrm{cm} \cdot \mathrm{sec}$, pressure $P_{0}=760$ torr, and the size $I_{0}=5-8 \mu \mathrm{m}$ [17]. Such parameters are substituted for (1) to acquire the natural frequencies $0.5 \mathrm{MHz}$ and $0.96 \mathrm{MHz}$ of the hydrogen producing bacteria. Hence, this study selected the single-crystal straight-beam longitudinalwave immersion transducer with natural frequencies of 0.5 and $1.0 \mathrm{MHz}$, while $5 \mathrm{MHz}$ is selected as the nonnatural frequency transducer for the comparison. After completing the required nutrient and strains, the proportion of $10: 1$ was placed in the reactor, as shown in Figure 3. Meanwhile, the thermostatic water bath was filled with water whose temperature was controlled at $33^{\circ} \mathrm{C} \sim 40^{\circ} \mathrm{C}$ by a temperature controlling machine. To ensure even distribution of the

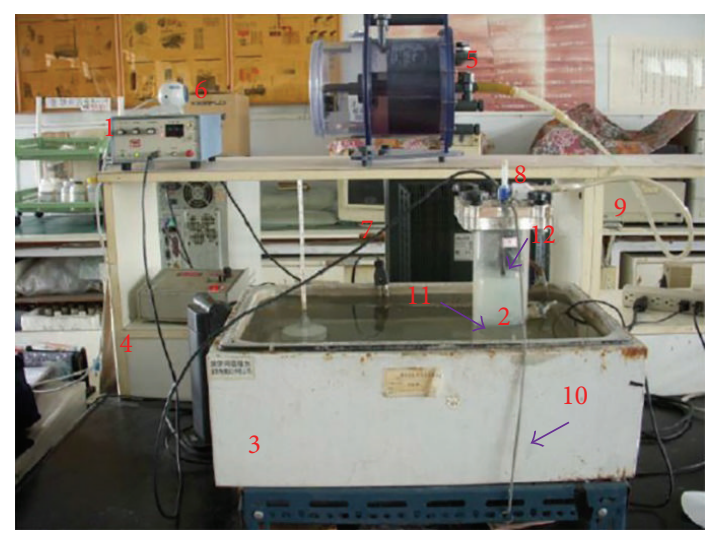

FIgURE 3: Experimental structure: 1: ultrasonic pulser, 2: reactor, 3: thermostatic bath, 4: thermostat, 5: flowmeter, 6: video camera, 7: computer, 8: sampling tube, 9: gas tube, 10: stirrer, 11: stirring stone, and 12: ultrasonic transducer.

measured liquid, a stirring rock was placed in the reactor, which was covered to create a closed space. The reactor was then placed in the thermostatic water bath with a stirrer beneath it to power the stirring stone for mixing nutrient and strains. Following the preparation, an ultrasonic transducer was connected to the pulse transmitter with the reactor lid and was soaked in the fermentation liquid. The other two empty holes on the reactor lid were placed in soft tubes for sampling and delivery of gas to the flowmeter. The ultrasonic pulser was further connected to an oscilloscope, leading to the incident and reflected waves being shown on the oscilloscope display for storage in a computer.

\subsubsection{Biohydrogen Production System}

(1) Strains and Nutrients. The experimental strains were taken from the wastewater in the end sedimentation tank of sewage treatment plants. This wastewater was mixed with bacterial strains, primarily bacillaceae. Numerous methods could be used for strain treatment, and this experiment adopted high temperature treatment. First, the bacteria liquid was placed in a beaker with a cover to prevent airborne competitors from entering the bacteria liquid. Second, the beaker, separated using an iron net, was heated to boiling on the heating plate. The boiled bacteria liquid was then stored for cooling. This process aimed to eliminate competitors to prevent them from generating other gases during the reaction.

Regarding the nutrient content, potato starch was used as the carbon source, ammonium hydrogen phosphate $\left(\mathrm{NH}_{4} \mathrm{H}_{2} \mathrm{PO}_{4}\right)$ as the nitrogen source, and dibasic sodium phosphate as the buffer salt for acid change, and all these materials included some microelements, as shown in Table 1. Proper carbon source, nitrogen source, buffer salt, and microelements were stirred in a pot with $1 \mathrm{~L} \mathrm{RO}$ water and then heated to boiling point. In the process, the solution was evenly stirred to prevent precipitation causing uneven nutrient concentration. The buffer salt served to stabilize the system $\mathrm{pH}$. During the metabolism in dark fermentation hydrogen production, the generation of acid and alcohols 
TABLE 1: Nutritional composition and formula.

\begin{tabular}{lc}
\hline Composition & Concentration mg/L \\
\hline Carbon source & $10 \mathrm{~g} / \mathrm{L}-20 \mathrm{~g} / \mathrm{L}-30 \mathrm{~g} / \mathrm{L}$ \\
$\mathrm{NH}_{4} \mathrm{H}_{2} \mathrm{PO}_{4}$ & 4500 \\
$\mathrm{Na}_{2} \mathrm{HPO}_{4}$ & 11867 \\
$\mathrm{~K}_{2} \mathrm{HPO}_{4}$ & 125 \\
$\mathrm{MgCl}_{2} \cdot 6 \mathrm{H}_{2} \mathrm{O}$ & 100 \\
$\mathrm{MnSO}_{4} \cdot 6 \mathrm{H}_{2} \mathrm{O}$ & 15 \\
$\mathrm{FeSO}_{4} \cdot 7 \mathrm{H}_{2} \mathrm{O}$ & 25 \\
$\mathrm{CuSO}_{4} \cdot 5 \mathrm{H}_{2} \mathrm{O}$ & 5 \\
$\mathrm{CoCl}_{2} \cdot 5 \mathrm{H}_{2} \mathrm{O}$ & 0.125 \\
\hline
\end{tabular}

could reduce system $\mathrm{pH}$ and further change the metabolism path of hydrogen production or even limit the fermentation for hydrogen production. The most commonly utilized buffer salts are $\mathrm{NH}_{4} \mathrm{H}_{2} \mathrm{PO}_{4}$ and $\mathrm{Na}_{2} \mathrm{HPO}$, which could increase hydrogen production and reduce the $\mathrm{CO}_{2} / \mathrm{H}_{2}$ ratio.

(2) Analysis. $\mathrm{H}_{2}$ and $\mathrm{CO}_{2}$ are the main gases produced in dark fermentation. This study thus selected Gas Chromatography analysis using a thermal conductivity detector. The separation column is a high-molecule ball with fixed length of $1.5 \mathrm{~m}$; the temperature at the injection port and detector was $100^{\circ} \mathrm{C}$, and the separation column temperature was $50^{\circ} \mathrm{C}$. Volatile acid and alcohols performed Gas Chromatography analysis with a flame ionization detector. The mobile gas was argon, which could separate methane, hydrogen, oxygen, carbon monoxide, and carbon dioxide. A spectrophotometer was utilized to measure the fermentation solution following ultrasonic exposure to understand the starch concentration of the fermented liquid. Iodine reagent caused the starch solution to appear blue violet. The main function was that amylase in starch formed a hollow helix to hold iodine molecules, causing the color change. Under certain starch concentrations, the concentration change was linearly related to the optical absorbance and could test starch decomposition in fermentation. The spectrophotometer, Shimadzu UV-1201, with the radiation wavelength $550 \mathrm{~nm}$ was used in this experiment.

(3) Fermentation Hydrogen Production Simulation. The modified Gompertz equation (9) was used to stimulate hydrogen production. Hydrogen production was simulated over time using the modified Gompertz equation, where the dynamic parameters $\left(\mathrm{H}_{\max }, R_{\max }\right.$, and $\left.\lambda\right)$ were established using the nonlinear regression function Sigma Plot [1]. Consider

$$
\mathrm{H}=\mathrm{H}_{\max } \exp \left\{-\exp \left[\frac{R_{\max , \mathrm{H}_{2}} \times e}{\mathrm{H}_{\max }}(\lambda-t)+1\right]\right\},
$$

where $\mathrm{H}$ represents accumulated produced hydrogen $(\mathrm{mL})$, $T$ represents fermentation duration $(h), \mathrm{H}_{\max }$ represents maximum hydrogen production potential $(\mathrm{mL}), R_{\max }$ represents maximum hydrogen production rate $(\mathrm{mL} / \mathrm{h})$, and $\lambda$ represents lag time (h).

(4) Calculation of Hydrogen Production Efficiency. Under the traditional process of transforming organic anaerobe into methane, carbon dioxide, and acids (including acetic acid, propanoic acid, and butyric acid), 1 mole sugar could produce 2 moles acetic acid, 4 moles hydrogen, and 2 moles carbon dioxide, as shown in (2). The actual hydrogen produced differed from the theoretical calculation, and the hydrogen production efficiency was represented as follows:

$$
\text { Efficiency }(\%)=\left(\frac{\text { Actual } \mathrm{H}_{2} \text { volume }}{\text { Theoretical } \mathrm{H}_{2} \text { volume }}\right) \times 100 \% \text {. }
$$

Theoretical hydrogen production could be shown as

Theoretical $\mathrm{H}_{2}$ volume

$$
=\frac{(\text { starch } \times 0.9 \times 0.7 \times 4 \times 0.08205 \times 298)}{162} .
$$

Substituting (10) for (11), the experimental efficiency was

$$
\begin{aligned}
& \text { Efficiency }(\%) \\
& \begin{aligned}
= & \left\{\frac{\text { Actual } \mathrm{H}_{2} \text { volume }}{[(\text { starch } \times 0.9 \times 0.7 \times 4 \times 0.08205 \times 298) / 162]}\right\} \\
& \times 100 \%,
\end{aligned}
\end{aligned}
$$

where Actual $\mathrm{H}_{2}$ volume represents hydrogen actually received in the experiment (liter), Theoretical $\mathrm{H}_{2}$ volume represents hydrogen volume received according to chemical theory (liter), Starch represents starch concentration $(\mathrm{g} / \mathrm{L})$ used in the experiment, 0.9 represents $1 \mathrm{~g}$ starch containing $0.1 \mathrm{~g}$ water and so the actual starch was $0.9 \mathrm{~g}, 0.7$ represents that the work volume of the reaction tank was just $0.7 \mathrm{~L}, 4$ represents that 1 mole sugar could produce 4 moles hydrogen, 0.08205 represents idea gas (constant), 298 represents absolute temperature, and 162 represents calculated number of units of starch.

3.2. Experimental Procedure. The experimental framework is shown in Figure 3. Ultrasound was applied to dark fermentation biohydrogen production to understand the mutual effects in the hydrogen production process, and the Taguchi Method was utilized to plan the experiment groups and times. The experimental procedure was as follows.

3.2.1. Parameter Selection. Orthogonal Array $L_{9}\left(3^{4}\right)$ in the Taguchi Method was applied to plan the experiment groups. Before determining the controlling factors and levels, experiments were performed using various controlling factors and levels to determine their effects on dark fermentation hydrogen production. Since the effects of ultrasound in exposing bacillaceae have not been studied and discussed, the number of controlling factors and levels for this study was as listed in Table 2.

(a) Ultrasonic exposure energy was first used as the controlling factor to clarify its effects on biohydrogen production. As the ultrasonic pulser could be adjusted to 2,4 , and 8 joules, the three values were the adjustable level numbers. 
TABLE 2: Experiment planning table.

\begin{tabular}{|c|c|c|c|c|}
\hline Factors & Specifics & Level 1 & Level 2 & Level 3 \\
\hline A & Power energy (joules) & 2 & 4 & 8 \\
\hline B & $\begin{array}{c}\text { Exposure time } \\
\text { (exposure/stop, } \mathrm{min} / \mathrm{min} \text { ) }\end{array}$ & $15 / 30$ & $15 / 15$ & All the time \\
\hline $\mathrm{C}$ & Frequency $(\mathrm{MHz})$ & 0.5 & 1 & 5 \\
\hline $\mathrm{D}$ & Starch concentration $(\mathrm{g} / \mathrm{L})$ & 10 & 20 & 30 \\
\hline
\end{tabular}

(b) Distinct ultrasonic exposure time periods were selected as the second controlling factor. The exposure time periods were $15 \mathrm{~min}$ exposure followed by $30 \mathrm{~min}$ rest, $15 \mathrm{~min}$ exposure followed by $15 \mathrm{~min}$ rest, and continuous exposure for full time.

(c) The third controlling factor was frequency of transducer exposure. The exposure frequency was changed to discuss the effects of ultrasound on biohydrogen production, and the adopted frequencies included $0.5 \mathrm{MHz}, 1 \mathrm{MHz}$, and $5 \mathrm{MHz}$.

(d) The effect of various starch concentrations on biohydrogen production was further discussed. Wang [10] found that hydrogen production peaked at starch concentration $20 \mathrm{~g} / \mathrm{L}$, and the volume production rate reached $106 \mathrm{~mL} / \mathrm{h}$. Complying with the level selection in the Taguchi Method, the present experimental parameters were considered the standard and varied by one unit in each direction. Consequently, 10, 20, and $30 \mathrm{~g} / \mathrm{L}$ starch were selected as the changed levels of nutrient concentration.

3.2.2. Experiment. By following Table 2 using the Taguchi Method, dark fermentation hydrogen production was combined with ultrasound to adjust the number of controlling factors and levels for the experiment.

(a) Strains were first boiled to delete the competitor and then cooled.

(b) Nutrient was prepared by mixing suitable starch, buffer salt, microelements, and $1 \mathrm{~L}$ boiled water that was being cooled.

(c) Strains and nutrient were placed in the reaction tank in a ratio of $1: 10$, and argon was infused for about 10 minutes to expel the air in the reaction tank.

(d) The external temperature of the reaction tank was controlled at $36^{\circ} \mathrm{C}$. A stirrer was placed under the reaction tank to drive the stirring rock to evenly mix the reaction tank liquid.

(e) Proper control conditions, as listed in Table 2, were added to the cultivation process.

3.2.3. Data Analysis. To increase the experiment reliability, nine sets of Taguchi's Orthogonal Arrays $L_{9}\left(3^{4}\right)$ were applied to acquire the maximum hydrogen production, hydrogen production rate, and lag time. The analyses are described below. (a) $S / N$ ratio, Response Table, or Response Diagram could be utilized to optimize the experimental conditions. Four quality characteristics, namely, experimental efficiency, hydrogen production rate, starch surplus ratio, and lag time, were analyzed in this study. The former two were Larger-the-better as the larger experimental efficiency and faster hydrogen production rate were better, while the latter two were Smaller-the-better as the lower starch surplus ratio indicated more starch use, and the shorter lag time helped reduce the fermentation time.

(b) The $S / N$ ratio result was used to determine the mean of the corresponding quality characteristics. Response Diagram could be applied to determine the required optimization conditions. In the process, the importance of different controlling factors in hydrogen production was also discussed.

3.2.4. Experiment Confirmation. The factor from $S / N$ ratio could reduce experiment variability. The factor in quality characteristics could then control the hydrogen production experiment being preceded under the optimal condition. $S / N$ ratio showed distinct optimization results from quality characteristics. Having compared the differences and selected the most suitable result for confirming the experiment, the verification demonstrated the best experimental combination of hydrogen production technology and mechanical effect.

\section{Results and Discussions}

To select the number of controlling factors and levels using the Taguchi Method, one of the curve diagrams of the experimental results after three repetitions is shown in Figure 4. The horizontal axis ( $x$-axis) represented the reaction time (h) while the vertical axis ( $y$-axis) represented the hydrogen production $(\mathrm{mL})$. According to Taguchi's Orthogonal Array $L_{9}\left(3^{4}\right)$, nine experiments and nine different symbols represented each experimental result. Table 3 represented the curve in Figure 4 showing the results of maximum hydrogen production, hydrogen production rate, and lag time. The maximum hydrogen production efficiency could be calculated from (10)-(12), and the rest (hydrogen production rate and lag time) could be directly analyzed without calculation. The fermented liquid could be measured for the starch surplus ratio. This experiment thus examined four quality characteristics, namely, hydrogen production efficiency, hydrogen production rate, starch surplus ratio, and lag time. Hydrogen production efficiency and hydrogen production rate were Larger-the-better, while lag time and starch surplus ratio were Smaller-the-better. The optimization process was divided into two steps. The first step reduced the variability, namely, to maximize $S / N$ ratio, while the other maximized the hydrogen production efficiency. Aiming at distinct optimization processes, the experimental results were further discussed.

The experimental results in Table 3 were repeated three times to obtain the mean hydrogen production efficiency, hydrogen production rate, starch surplus ratio, lag time, and 


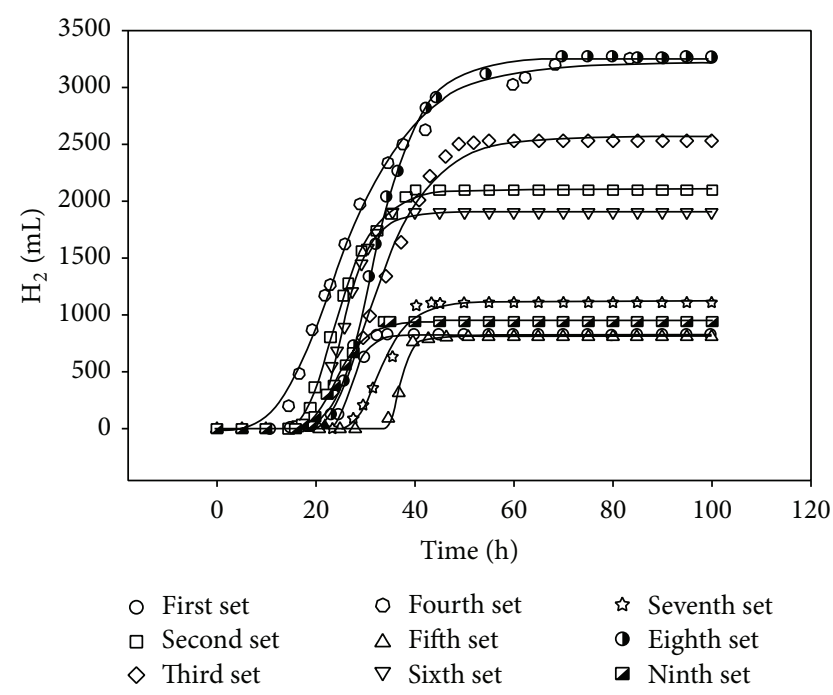

FIGURE 4: The curve diagram showing the first experimental results using the Taguchi Method.

TABLE 3: The effects of biological $\mathrm{H}_{2}$ production using the Taguchi Method.

\begin{tabular}{lccc}
\hline Experimental sets & $\mathrm{H}_{\max }(\mathrm{mL})$ & $R_{\max }(\mathrm{mL} / \mathrm{h})$ & $\lambda(\mathrm{h})$ \\
\hline 1 & 889.79 & 118.93 & 24.08 \\
2 & 2126.58 & 147.42 & 17.72 \\
3 & 2785.89 & 115.27 & 22.12 \\
4 & 3141.07 & 119.35 & 12.50 \\
5 & 811.02 & 185.28 & 185.28 \\
6 & 2087.64 & 164.75 & 20.09 \\
7 & 1370.16 & 86.55 & 27.54 \\
8 & 3199.82 & 198.66 & 24.16 \\
9 & 1079.55 & 79.31 & 18.81 \\
\hline
\end{tabular}

$S / N$ ratio. All the values were listed in Table 4 . The second to the fifth columns represented the variability of the controlling factors and levels corresponding to the nine experiments in Taguchi's Orthogonal Array. To reduce the variability, Table 5 shows the factor Response Table of hydrogen production efficiency $S / N$ ratio calculated using the experimental results in Table 4. The level values under column A presented the effects of variability, and the variability among different levels could be regarded as the effect of controlling factors on $S / N$. The range in the table showed the maximum range of variability, where the larger variability in Rank is more important. As the $S / N$ ratio was expected to be Largerthe-better, the optimal experimental settings for hydrogen production efficiency showed the conditions of A2B2C1D3. This implied ultrasonic exposure energy 4 joules, exposure time $15 \mathrm{~min} / \mathrm{stop}$ for $15 \mathrm{~min}$, transducer frequency $0.5 \mathrm{MHz}$, and starch concentration $30 \mathrm{~g} / \mathrm{L}$. The Response Table of $S / N$ ratio showed that starch concentration (factor $\mathrm{D}$ ) was the most significant factor in the experimental results, followed by exposure intensity, frequency, and time. In this case, the ultrasonic exposure intensity was $72.46 \%$ significance when compared with the starch concentration that was always used by the traditional biohydrogen production method. Table 6 showed the $S / N$ ratio of hydrogen production rate. Similar to the optimization results of hydrogen production efficiency, the optimal results occurred with ultrasonic energy at level 2, exposure time at level 2, transducer frequency at level 1, and starch concentration at level 3. Starch concentration was also the main controlling factor.

By analyzing the starch surplus ratio, Table 7 listed the optimal settings for $S / N$ ratio as ultrasonic exposure energy at level 2, exposure time at level 1, transducer frequency at level 2, and starch concentration at level 2. Comparing hydrogen production efficiency and hydrogen production rate revealed that the exposure energy had the same level, while the other three controlling factors were different. With the four controlling factors, starch concentration showed the largest effect on starch surplus ratio, followed by exposure frequency. By analyzing the lag time, the optimal settings for $S / N$ ratio, as listed in Table 8, included ultrasonic energy at level 2, full-time exposure at level 3, transducer frequency at level 2, and starch concentration at level 2. From the table, the transducer frequency showed the strongest effect on lag time, followed by starch concentration.

According to Tables 5-8, besides hydrogen production efficiency and hydrogen production rate sharing a common optimal level with various controlling factors and starch surplus ratio and lag time exhibiting different exposure times, the other factors exhibited the same optimal level. In the reaction of controlling factors, all experiments obtained the largest $S / N$ ratio from the controlling factors when the ultrasonic energy totaled 4 joules, and the level number selected by the other three controlling factors was distinct for different quality characteristics. Starch concentration was considered crucial in three quality characteristics, while the key factor was the transducer frequency under the lag time. Since the four quality characteristics were not consistent in the variability analysis of reducing $S / N$ ratio, hydrogen production efficiency and rate were first considered during the second optimization phase. The quality characteristics were shown in Figures 5 and 6 , where the $x$-axis A1 represented the reaction given controlling factor $\mathrm{A}$ and level number 1 . The $y$-axis represented the hydrogen production efficiency and rate. From Figure 5, starch concentration showed the largest change, followed by exposure energy, exposure frequency, and exposure time. In Figure 6, the extent of the influences of exposure energy and exposure time switched so that the largest influence remained starch concentration, but the smallest effect was exposure energy. Figures 3 and 4 also identify the experimental parameters for hydrogen production efficiency and hydrogen production rate optimization as being

$$
\text { A2, B2, C1, D3. }
$$

The determined parameters corresponded to Tables 5 and 6 , and thus the optimal hydrogen production efficiency and hydrogen production rate confirmed the experiment results when reduced variability was first considered. Table 9 showed the comparison between the confirmation experiment based on (13) as the optimization and the maximum value of the 
TABLE 4: Experiments examining the effect of ultrasonic influences on hydrogen production.

\begin{tabular}{|c|c|c|c|c|c|c|c|c|c|c|c|c|}
\hline \multirow[b]{2}{*}{ Exp. } & \multirow[b]{2}{*}{ A } & \multirow[b]{2}{*}{ B } & \multirow[b]{2}{*}{$\mathrm{C}$} & \multirow[b]{2}{*}{$\mathrm{D}$} & \multicolumn{2}{|c|}{ Production efficiency } & \multicolumn{2}{|c|}{ Production rate } & \multicolumn{2}{|c|}{ Starch surplus ratio } & \multicolumn{2}{|c|}{$\lambda(\mathrm{h})$} \\
\hline & & & & & $\begin{array}{c}\text { Average } \\
(\%)\end{array}$ & $\begin{array}{l}S / N \\
(\mathrm{~dB})\end{array}$ & $\begin{array}{c}\text { Average } \\
(\mathrm{mL} / \mathrm{h})\end{array}$ & $\begin{array}{l}S / N \\
(\mathrm{~dB})\end{array}$ & $\begin{array}{c}\text { Average } \\
(\%)\end{array}$ & $\begin{array}{l}S / N \\
(\mathrm{~dB})\end{array}$ & $\begin{array}{c}\text { Average } \\
\text { (h) }\end{array}$ & $\begin{array}{l}S / N \\
(\mathrm{~dB})\end{array}$ \\
\hline 1 & 1 & 1 & 1 & 1 & 18.94 & 18.94 & 85.40 & 37.81 & 10.27 & -20.31 & 22.54 & -27.45 \\
\hline 2 & 1 & 2 & 2 & 2 & 22.66 & 26.50 & 131.47 & 42.10 & 7.77 & -17.86 & 16.35 & -24.44 \\
\hline 3 & 1 & 3 & 3 & 3 & 23.02 & 27.10 & 164.77 & 43.60 & 8.32 & -18.51 & 22.03 & -26.91 \\
\hline 4 & 2 & 1 & 2 & 3 & 27.11 & 28.46 & 142.18 & 42.87 & 7.43 & -17.54 & 15.68 & -24.03 \\
\hline 5 & 2 & 2 & 3 & 1 & 21.82 & 26.67 & 127.01 & 40.10 & 9.40 & -19.60 & 30.18 & -29.65 \\
\hline 6 & 2 & 3 & 1 & 2 & 26.76 & 28.17 & 149.62 & 43.40 & 8.38 & -18.54 & 17.32 & -25.10 \\
\hline 7 & 3 & 1 & 3 & 2 & 21.12 & 25.23 & 129.84 & 40.20 & 7.73 & -18.18 & 24.47 & -28.10 \\
\hline 8 & 3 & 2 & 1 & 3 & 26.68 & 28.34 & 218.88 & 46.70 & 9.04 & -19.30 & 22.10 & -26.91 \\
\hline 9 & 3 & 3 & 2 & 1 & 20.23 & 25.82 & 66.23 & 36.04 & 9.50 & -19.61 & 20.69 & -26.87 \\
\hline
\end{tabular}

TABLE 5: Hydrogen production efficiency for different $S / N$ ratios.

\begin{tabular}{lcccc}
\hline & $\mathrm{A}$ & $\mathrm{B}$ & $\mathrm{C}$ & $\mathrm{D}$ \\
\hline Level 1 & 26.26 & 26.29 & 27.23 & 25.89 \\
Level 2 & 27.77 & 27.17 & 26.93 & 26.63 \\
Level 3 & 26.46 & 27.03 & 26.33 & 27.97 \\
Range & 1.50 & 0.88 & 0.90 & 2.07 \\
Rank & 2 & 4 & 3 & 1 \\
\hline
\end{tabular}

TABLE 6: Hydrogen production rate for different $S / N$ ratios.

\begin{tabular}{lcccc}
\hline & $\mathrm{A}$ & $\mathrm{B}$ & $\mathrm{C}$ & $\mathrm{D}$ \\
\hline Level 1 & 41.17 & 40.29 & 42.64 & 37.98 \\
Level 2 & 42.12 & 42.97 & 40.34 & 41.90 \\
Level 3 & 40.98 & 41.01 & 41.30 & 44.39 \\
Range & 1.14 & 2.67 & 2.30 & 6.41 \\
Rank & 4 & 2 & 3 & 1 \\
\hline
\end{tabular}

TABLE 7: Starch surplus ratio for different $S / N$ ratios.

\begin{tabular}{lcccc}
\hline & A & B & C & D \\
\hline Level 1 & -18.89 & -18.68 & -19.38 & -19.84 \\
Level 2 & -18.56 & -18.92 & -18.34 & -18.19 \\
Level 3 & -19.03 & -18.89 & -18.76 & -18.45 \\
Range & 0.47 & 0.25 & 1.05 & 1.65 \\
Rank & 3 & 4 & 2 & 1 \\
\hline
\end{tabular}

TABLE 8: Lag time for different $S / N$ ratios.

\begin{tabular}{lcccc}
\hline & $\mathrm{A}$ & $\mathrm{B}$ & $\mathrm{C}$ & $\mathrm{D}$ \\
\hline Level 1 & -26.27 & -26.53 & -26.49 & -27.99 \\
Level 2 & -26.26 & -27.00 & -25.11 & -25.88 \\
Level 3 & -27.29 & -26.29 & -28.22 & -25.95 \\
Range & 1.03 & 0.71 & 3.11 & 2.11 \\
Rank & 3 & 4 & 1 & 2 \\
\hline
\end{tabular}

nine experiments in Taguchi's Orthogonal Array (Table 4). In terms of hydrogen production efficiency, the optimal combination of quality characteristics and $S / N$ ratio was $19.11 \%$ better than the maximum value obtained from the nine experiments in Taguchi's Orthogonal Array. Regarding

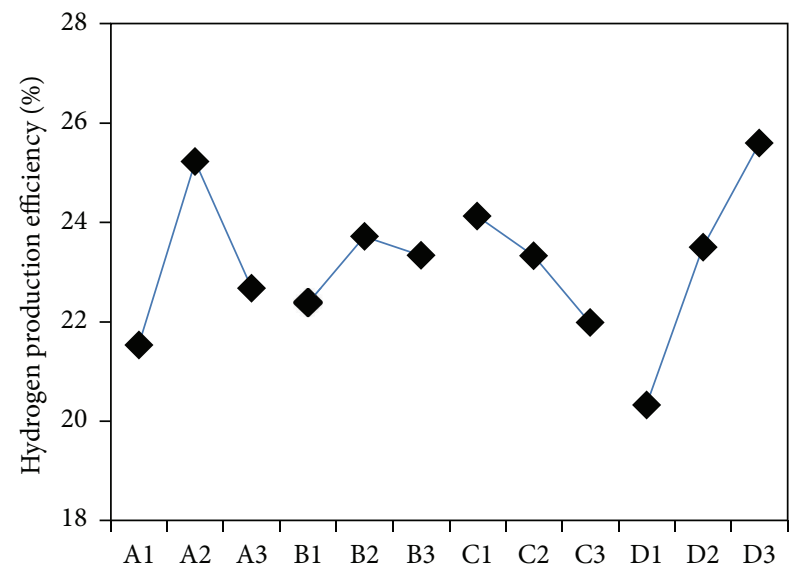

FIgURE 5: The Response Diagram of hydrogen production efficiency for different levels.

the hydrogen production rate, the optimal settings from the nine experiments in Taguchi's Orthogonal Array was 23.82\% better. To summarize the above optimization and confirmation experiments, the optimal settings were A2, B2, C1, and D3 when considering the maximum hydrogen production efficiency and rate. That is, the best hydrogen production occurred with ultrasonic energy 4 joules, exposure for $15 \mathrm{~min}$ followed by no exposure for $15 \mathrm{~min}$, transducer $0.5 \mathrm{MHz}$, and starch concentration $30 \mathrm{~g} / \mathrm{L}$.

\section{Conclusion}

Introducing the Taguchi Method, the number of experiments could be significantly reduced by the Orthogonal Array, which is determined from controlling factors and parameters. Two steps in optimization process are accomplished. The variability of experiment is reduced and then the hydrogen production efficiency and rate are maximized. For verifying the analyzed results, the experiment is performed as follows.

(1) The optimal hydrogen production efficiency is $32.29 \%$, which is $19.11 \%$ higher than the maximum in Taguchi’s Orthogonal Array. 
TABLE 9: The results of the confirmation experiment.

\begin{tabular}{lccc}
\hline Quality indicators & Orthogonal Array & Optimal condition & Improvement $(\%)$ \\
\hline Production efficiency $(\%)$ & 27.11 & 32.29 & 19.11 \\
Production rate $(\mathrm{mL} / \mathrm{h})$ & 218.88 & 271.01 & 23.82 \\
\hline
\end{tabular}

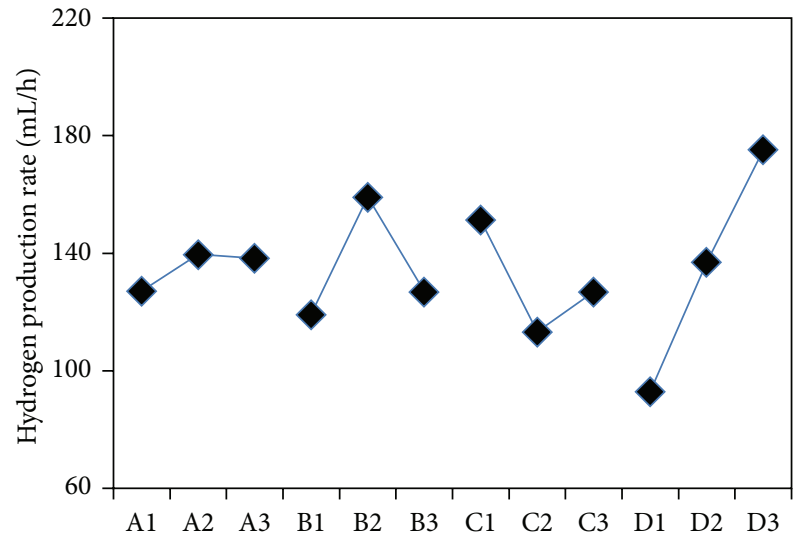

FIGURE 6: The Response Diagram of hydrogen production rate for different levels.

(2) The optimal hydrogen production rate is $271.01 \mathrm{~mL} / \mathrm{h}$, which is $23.82 \%$ higher than in Taguchi's Orthogonal Array.

(3) Hydrogen production efficiency and hydrogen production rate are optimized given ultrasonic energy 4 joules, $15 \mathrm{~min}$ exposure followed by $15 \mathrm{~min}$ rest, transducer $0.5 \mathrm{MHz}$, and starch concentration $30 \mathrm{~g} / \mathrm{L}$.

(4) Within the four controlling factors, starch concentration most strongly affects the experimental results. For hydrogen production efficiency, exposure intensity ranks second, while for exposure time hydrogen production rate ranks second.

(5) The ultrasonic mechanical effects always own different significances on biohydrogen production. For example, the ultrasonic exposure intensity possesses $72.46 \%$ significance when compared with the starch application on the consideration of hydrogen production efficiency. At the same time, the ultrasonic frequency shows the strongest effect on the concentration of the lag time.

Besides developing a suitable medium composition, this study also combines ultrasonic mechanical effects with biological reactors to perform dark fermentation hydrogen production. The Taguchi Method is also utilized to discuss the relationship among parameters in the hydrogen production process and is expected to optimize the hydrogen production conditions and further understand the effects of ultrasound on microorganisms.

\section{Conflict of Interests}

The authors declare that there is no conflict of interests regarding the publication of this paper.

\section{Acknowledgments}

This work was partially supported by the National Science Council, Taiwan, under Grant NSC-99-2221-E-244-004. Ted Knoy is appreciated for his editorial assistance.

\section{References}

[1] W. T. Coakley, D. Hampton, and F. Dunn, "Quantitative relationships between ultrasonic cavitation and effects upon amoebae at $1 \mathrm{MHz}$," Journal of the Acoustical Society of America, vol. 50, no. 6, pp. 1546-1553, 1971.

[2] W. T. Coakley and F. Dunn, "Degradation of DNA in highintensity focused ultrasonic fields at $1 \mathrm{MHz}$," Journal of the Acoustical Society of America, vol. 50, pp. 1539-1545, 1971.

[3] W. T. Coakley, R. C. Brown, C. J. James, and R. K. Gould, “The inactivation of enzymes by ultrasonic cavitation at $20 \mathrm{kHz}$," Archives of Biochemistry and Biophysics, vol. 159, no. 2, pp. 722729, 1973.

[4] F. I. K. Ahmed and C. Russell, "Synergism between ultrasonic waves and hydrogen peroxide in the killing of micro organisms," Journal of Applied Bacteriology, vol. 39, no. 1, pp. 31-40, 1975.

[5] D. A. Dooley, S. Z. Child, E. L. Carstensen, and M. W. Miller, "The effects of continuous wave and pulsed ultrasound on rat thymocytes in vitro," Ultrasound in Medicine and Biology, vol. 9, no. 4, pp. 379-384, 1983.

[6] D. W. Van, "The effect of ultraviolet light, cavitational flow and ultrasound on protozoan cysts and oocysts, bacteriophages and Clostridium," Water SA, vol. 28, pp. 16-22, 2002.

[7] D. M. Broda, "The effect of peroxyacetic acid-based sanitizer, heat and ultrasonic waves on the survival of Clostridium estertheticum spores in vitro," Letters in Applied Microbiology, vol. 45, no. 3, pp. 336-341, 2007.

[8] C. N. Lin, Hydrogen Production with Immobilized Cells [M.S. dissertation], Feng Chia University, Taichung, Taiwan, 2002.

[9] C. C. Chen, Hydrogen production in an anaerobic Continuousflow Stirred Tank Reactor (CSTR) System [Ph.D. dissertation], Feng Chia University, Taichung, Taiwan, 2002.

[10] C. H. Wang, Fermentation strategies for biomass hydrogen production using anaerobic bacterial microflora [Ph.D. dissertation], Feng Chia University, Taichung, Taiwan, 2006.

[11] M. Modigell, M. Schumacher, V. V. Teplyakov, and V. B. Zenkevich, "A membrane contactor for efficient $\mathrm{CO}_{2}$ removal in biohydrogen production," Desalination, vol. 224, no. 1-3, pp. 186-190, 2008.

[12] G. Antonopoulou, H. N. Gavala, I. V. Skiadas, K. Angelopoulos, and G. Lyberatos, "Biofuels generation from sweet sorghum: 
fermentative hydrogen production and anaerobic digestion of the remaining biomass," Bioresource Technology, vol. 99, no. 1, pp. 110-119, 2008.

[13] S. M. Kotay and D. Das, "Biohydrogen as a renewable energy resource-Prospects and potentials," International Journal of Hydrogen Energy, vol. 33, no. 1, pp. 258-263, 2008.

[14] S. Manish and R. Banerjee, "Comparison of biohydrogen production processes," International Journal of Hydrogen Energy, vol. 33, no. 1, pp. 279-286, 2008.

[15] C. L. Su, The biological activation of fairy shrimp cyst induced by ultrasound exposure and light [M.S. thesis], National Sun Yatseen University, Kaohsiung, Taiwan, 2011.

[16] G. Cum, G. Galli, R. Gallo, and A. Spadaro, "Role of frequency in the ultrasonic activation of chemical reactions," Ultrasonics, vol. 30, no. 4, pp. 267-270, 1992.

[17] R. Pratt, "Studies on Chlorella vulgaris. XI. Relation between surface tension and accumulation of chlorellin," American Journal of Botany, vol. 35, no. 9, pp. 634-637, 1948. 

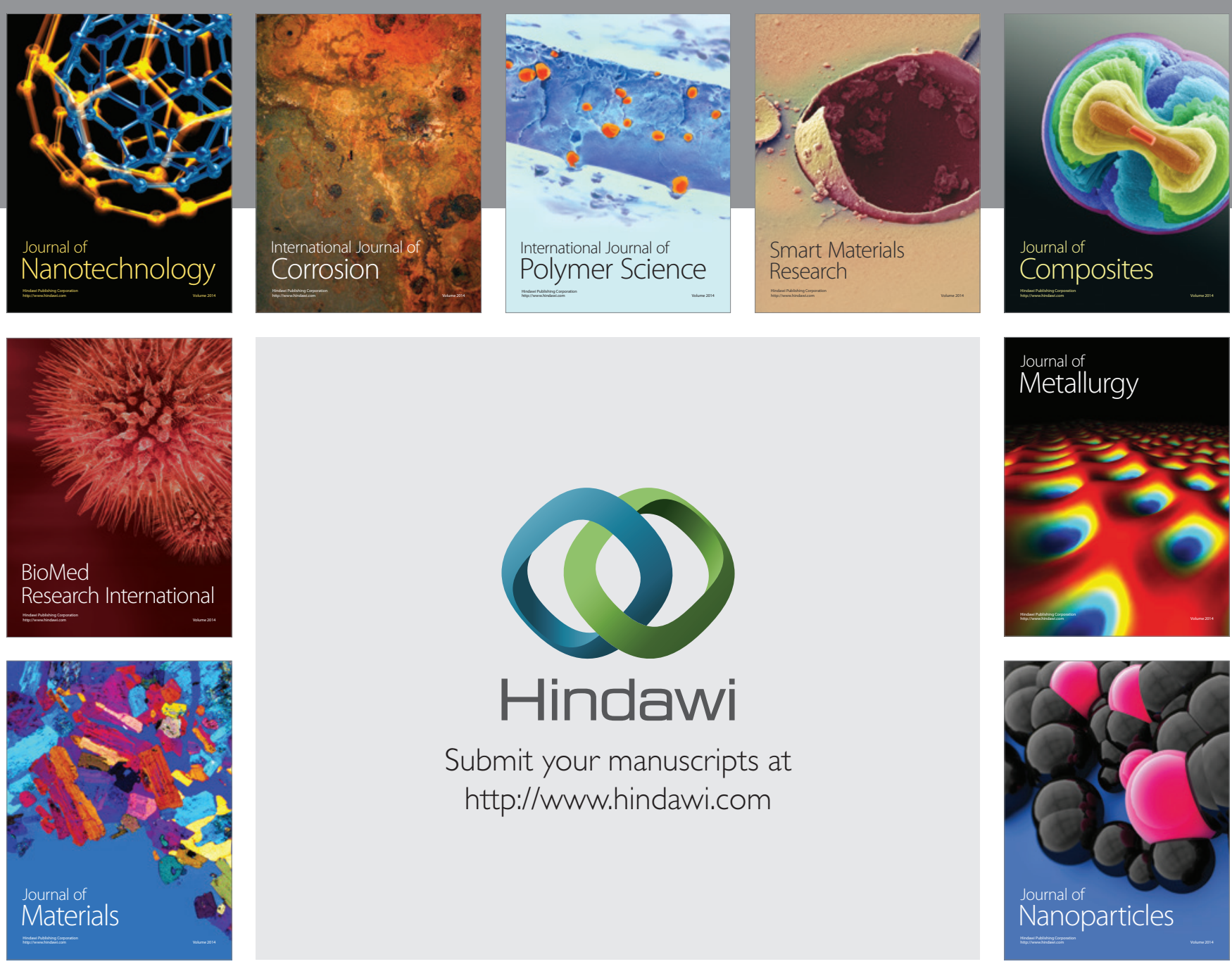

Submit your manuscripts at http://www.hindawi.com
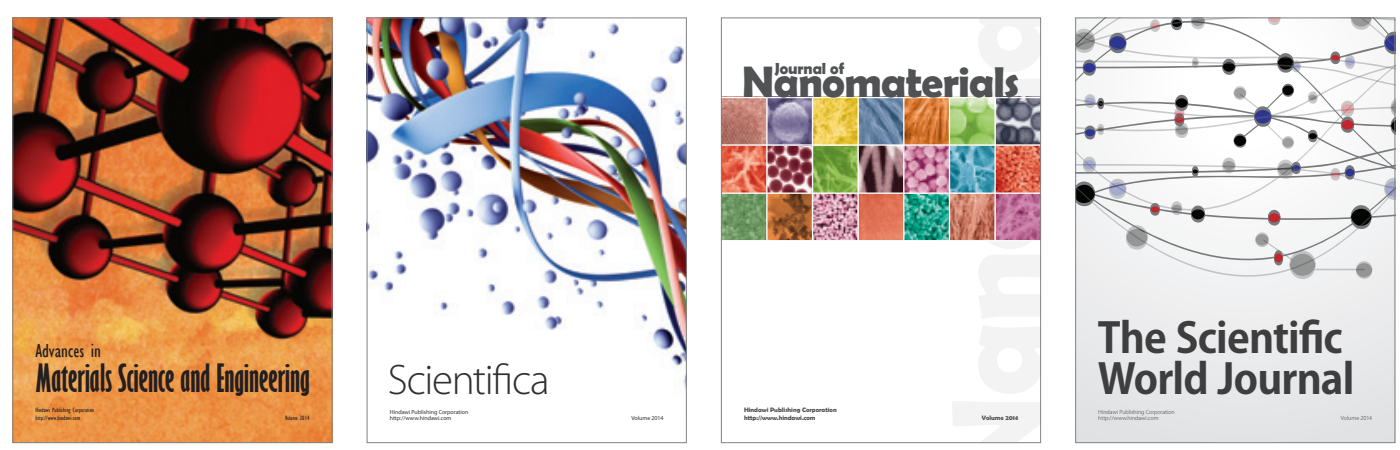

\section{The Scientific World Journal}
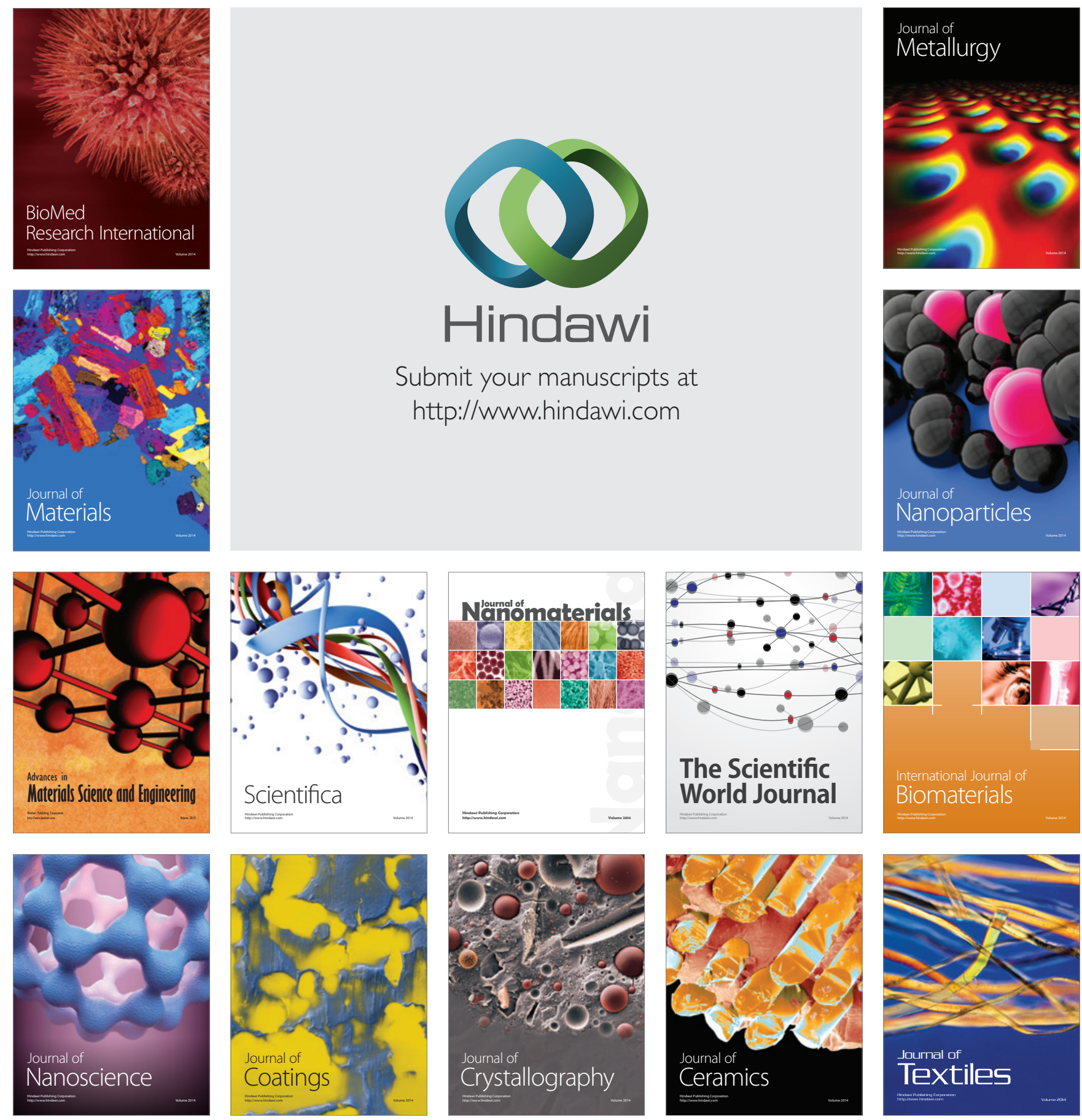